\title{
Video-assisted thoracic surgery lobectomy oncologically is equal to the open thoracotomy one
}

\author{
Marcin Zieliński \\ Department of Thoracic Surgery, Pulmonary Hospital, Zakopane, Poland \\ Correspondence to: Marcin Zieliński, MD, PhD. Department of Thoracic Surgery, Pulmonary Hospital, Ul. Gładkie 1, 34 500 Zakopane, Poland. \\ Email: marcinz@mp.pl. \\ Provenance: This is an invited article commissioned by the Academic Editor Dr. Feng Li (Department of Surgery, Competence Center of Thoracic \\ Surgery, Charité University Hospital Berlin, Berlin, Germany). \\ Comment on: Yang CJ, Kumar A, Klapper JA, et al. A National Analysis of Long-term Survival Following Thoracoscopic Versus Open Lobectomy for \\ Stage I Non-small-cell Lung Cancer. Ann Surg 2019;269:163-71.
}

Submitted Sep 01, 2019. Accepted for publication Sep 26, 2019.

doi: 10.21037/atm.2019.09.146

View this article at: http://dx.doi.org/10.21037/atm.2019.09.146

The introduction of minimally invasive video-assisted thoracic surgery (VATS) almost three decades ago has substantially changed the operative treatment of non-small cell lung cancer (NSCLC). For the first period of time, the main issue was technical feasibility and safety of VATS pulmonary resections, especially in case of lobectomy. With a passage of years, after wide popularization of VATS among thoracic surgeons it became clear that VATS lobectomy was an equivalent of the open thoracotomy procedure in terms of safety. However, only in recent years, the superiority of VATS lobectomy over open thoracotomy lobectomy in terms of lesser postoperative pain and better quality of life has been shown in prospective randomized trial presented by Bendixen et al. (1). Despite some concerns about and adequacy of lymphadenectomy during VATS procedures in regard to the number of resected lymph nodes, it was found in many publications that VATS was no different from open thoracotomy procedures. The last issue that remained to be proven is an oncological value of VATS lobectomy for NSCLC, especially concerning the results of long term survival. The study of Yang et al. was intended to fill this gap in our knowledge (2). The authors compared retrospectively the long-term survival of the open and VATS lobectomy for early stage clinical T1-2, N0, M0 NSCLC based on the analysis of the National Cancer Data Base (United States) with the use of propensity score matching. The advantages of
VATS included a significant shortening of a median length of hospitalization ( 5 vs. 6 days, $\mathrm{P}<0.001$ ), an improved 5 -year survival $(66.0 \%$ vs. $62.5 \%, \mathrm{P}=0.026)$. The VATS and the open thoracotomy approaches did not differ for the nodal upstaging $(11.2 \%$ vs. $12.5 \%, \mathrm{P}=0.46)$, and 30 -day mortality $(1.7 \%$ vs. $2.5 \%, \mathrm{P}=0.14)$. In the propensity-matched analysis of 2928 patients, there were no significant differences in 5-year survival between the VATS and open groups (66.3\% vs. 65.8\%, $\mathrm{P}=0.92)$.

What are the advantages of the study by Yang et al.? First of all, a relatively homogenous group of patients with stage I NSCLC, including a high number of patients, all of them operated on in 2010. The patients belonged to the various race and represented different levels of wealthiness expressed by different types of insurance. Therefore, the patients were operated not only by high-rank thoracic surgeons but probably also by residents. Both groups were also matched for the other factors, with no differences between any of these factors. Obviously, a large number of the analyzed patients and clearly presented methodology of the study made it more reliable.

What are the shortcomings of the study? No doubt, the use of the 6th edition of IASLC classification of NSCLC might be misleading, with some tumors with diameter 5-7 cm, described in the study as T2, while they are T3, according to the current 8 th edition of IASLC classification. The other clear disadvantage of the study is its retrospective 
character not entirely compensated by the statistical analysis with propensity score matching.

Obviously, prospective randomized study would have been more convincing.

Are the conclusions of the study of Yang et al. that VATS did not impair oncologic outcomes when used for earlystage lung cancer and suggested the need for broader implementation of VATS techniques still valid for the community of thoracic surgeons or they need a further confirmation in the prospective randomized trial?

It seems, that such expectations would be futile. VATS lobectomy has become an accepted technique for the treatment of stage I NSCLC, proved to be superior to open thoracotomy approach for the reduced pain and better quality of life. Yang et al. showed that with growing experience of thoracic surgeons even the last shortcoming of the VATS approach, like less complete lymphadenectomy could be overcome, with no difference between the VATS and open thoracotomy approaches in terms of the number of resected lymph nodes.

Concluding, VATS lobectomy should be regarded as a procedure oncologically equal to the open thoracotomy lobectomy and should become a standard of care for the treatment of stage I NSCLC.

Cite this article as: Zieliński M. Video-assisted thoracic surgery lobectomy oncologically is equal to the open thoracotomy one. Ann Transl Med 2019;7(Suppl 8):S328. doi: 10.21037/atm.2019.09.146

\section{Acknowledgments}

None.

\section{Footnote}

Conflicts of Interest: The author has no conflicts of interest to declare.

Ethical Statement: The author is accountable for all aspects of the work in ensuring that questions related to the accuracy or integrity of any part of the work are appropriately investigated and resolved.

\section{References}

1. Bendixen M, Jørgensen OD, Kronborg C, et al. Postoperative pain and quality of life after lobectomy via video-assisted thoracoscopic surgery or anterolateral thoracotomy for early stage lung cancer: a randomised controlled trial. Lancet Oncol 2016;17:836-44.

2. Yang CJ, Kumar A, Klapper JA, et al. A National Analysis of Long-term Survival Following Thoracoscopic Versus Open Lobectomy for Stage I Non-small-cell Lung Cancer. Ann Surg 2019;269:163-71. 